A Chemical Kinetic Modeling Study of the Effects of Oxygenated Hydrocarbons on Soot Emissions from Diesel Engines

C. K. Westbrook, W. J. Pitz, H. J. Curran

November 14, 2005

Journal of Physical Chemistry A 
This document was prepared as an account of work sponsored by an agency of the United States Government. Neither the United States Government nor the University of California nor any of their employees, makes any warranty, express or implied, or assumes any legal liability or responsibility for the accuracy, completeness, or usefulness of any information, apparatus, product, or process disclosed, or represents that its use would not infringe privately owned rights. Reference herein to any specific commercial product, process, or service by trade name, trademark, manufacturer, or otherwise, does not necessarily constitute or imply its endorsement, recommendation, or favoring by the United States Government or the University of California. The views and opinions of authors expressed herein do not necessarily state or reflect those of the United States Government or the University of California, and shall not be used for advertising or product endorsement purposes. 


\title{
A Chemical Kinetic Modeling Study of the Effects of Oxygenated Hydrocarbons on Soot Emissions from Diesel Engines
}

\author{
Charles K. Westbrook*, William J. Pitz and Henry J. Curran ${ }^{1}$ \\ Lawrence Livermore National Laboratory \\ P.O. Box 808, Livermore, CA 94550
}

* To whom correspondence should be addresses. Email: westbrook1@1lnl.gov
1 National University of Ireland, University College Galway, Galway, Ireland

Submitted to J. Phys. Chem. A

\begin{abstract}
A detailed chemical kinetic modeling approach is used to examine the phenomenon of suppression of sooting in diesel engines by addition of oxygenated hydrocarbon species to the fuel. This suppression, which has been observed experimentally for a few years, is explained kinetically as a reduction in concentrations of soot precursors present in the hot products of a fuel-rich diesel ignition zone when oxygenates are included. Oxygenates decrease the overall equivalence ratio of the igniting mixture, producing higher ignition temperatures and more radical species to consume more soot precursor species, leading to lower soot production. The kinetic model is also used to show how different oxygenates, ester structures in particular, can have different soot-suppression efficiencies due to differences in molecular structure of the oxygenated species.
\end{abstract}




\section{Introduction}

Soot emissions from diesel engines continue to be a serious environmental concern. While significant reductions have been achieved in recent years, legislated limits are being steadily tightened ${ }^{1}$, and further improvements will require a much more fundamental understanding of soot production and evolution to meet these regulations. Many experimental, theoretical and computer modeling studies have been devoted to these problems in order to refine our understanding of the reaction pathways producing and consuming soot in engines and flames. Attention has been given to the fact that different hydrocarbon fuels can produce significantly different quantities of $\operatorname{soot}^{2}$ and that modifications of soot-producing fuels can lead to considerable reductions in soot production. In particular, the use of oxygenated fuels and fuel additives has demonstrated the potential to reduce soot emissions from diesel engines.

In a recent experimental study, Miyamoto et al. ${ }^{3}$ found that soot emissions from diesel engines were reduced when oxygenated hydrocarbons were blended with the regular diesel fuel. The amount of soot reduction depended on the total amount of oxygen added to the diesel fuel, and each of the oxygenated species added to the fuel (di-n-butyl ether, ethylhexyl acetate, ethylene glycol mono-nbutyl ether, and diethylene glycol dimethyl ether) had approximately the same effectiveness in reducing soot emissions when measured in terms of the amount of oxygen added to the fuel. With each additive, soot emissions declined steadily as the additive concentration increased, and by the time the oxygen content of 


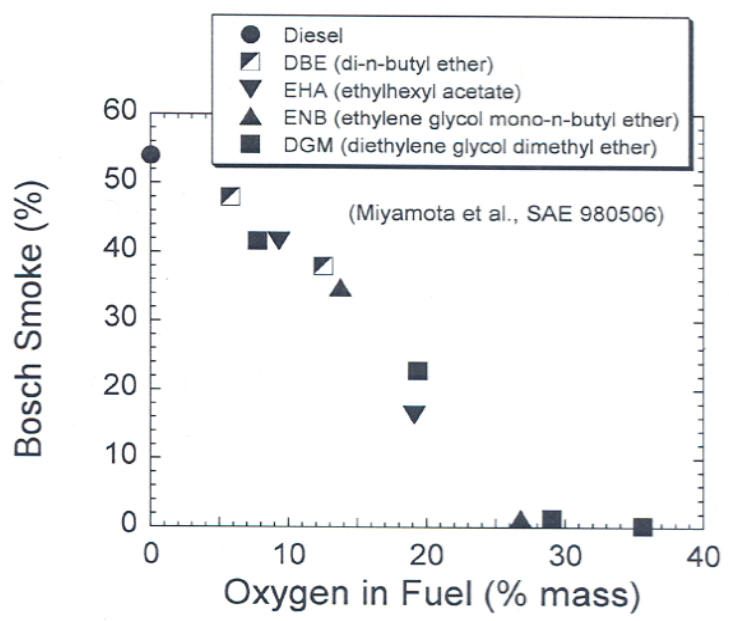

Figure 1. Variations in experimentally measured soot emissions from a diesel engine $^{3}$ with oxygenated species additions.

the fuel reached 25 - 30\% by mass, virtually all soot emissions had disappeared, as summarized in Figure 1. While these results were very encouraging signs that soot emissions could be reduced by modifying the diesel fuel composition, the phenomenological results could not be explained in fundamental terms.

Subsequent experimental engine studies ${ }^{4-11}$ have extended these results to other oxygenated species. In addition, Litzinger et al. ${ }^{12-14}$ have recently combined experimental and kinetic modeling analysis of the soot-reducing effects of oxygenated species (i.e., ethanol and dimethyl ether) on sooting laminar premixed and diffusion ethane-air and ethylene-air flames, and while these flames and fuel are quite distinct from diesel combustion, they provide valuable chemical insights into soot reduction chemistry. 
The present work uses detailed chemical kinetic modeling to address sooting reduction in diesel engines by oxygenated additives and explain the behavior in fundamental terms. Basic understanding from this kinetic modeling may suggest other mechanisms for modifying sooting processes. The same analysis can make it possible to evaluate the soot reducing potential of other oxygenated species, including commercially important biodiesel fuels.

\section{Modeling Approach}

Our kinetic modeling study is constructed upon a conceptual model for diesel combustion developed by Dec and his colleagues, who used an extensive set of laser-based diagnostic techniques ${ }^{15-21}$ to describe the major chemical and physical steps that occur during diesel combustion. Briefly, according to this picture, shown in Figure 2, shortly before the end of the compression stroke of the piston, diesel fuel is injected into hot, highly compressed air and residual combustion products in the combustion chamber in a number of liquid jets. Each

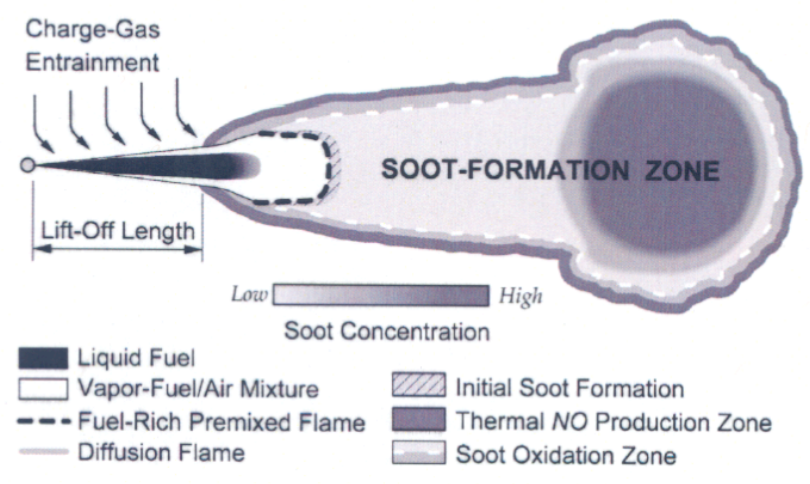

Figure 2. Phenomenological description of the major features of diesel combustion from experimental studies of Dec ${ }^{15}$. 
fuel jet vaporizes rapidly and entrains and mixes with hot air. The hot air steadily raises the temperature of the vaporized fuel while simultaneously increasing the ratio of air to fuel. This mixture eventually ignites in the gas phase while still under quite fuel-rich conditions, with a local equivalence ratio $\phi$ of about 3 (i.e., three times as much fuel as could be fully oxidized by the air mixed locally with the fuel). The location of this fuel-rich premixed ignition is identified as the dashed curve in Figure 2.

The products of this ignition cannot be oxidized completely, due to the absence of any more oxygen. Therefore these incompletely oxidized species such as $\mathrm{CO}, \mathrm{H}_{2}$ and small, intermediate hydrocarbon species including acetylene, ethene, propene and others then react to produce soot ${ }^{17-19}$ which is later consumed in a diffusion flame environment ${ }^{19}$ farther downstream of the ignition region. The same unsaturated hydrocarbon species have been identified as major contributors to soot production in both diesel engines and laboratory flames $^{21-32}$.

Our kinetic modeling approach is to compute the rich, premixed diesel ignition, using detailed chemical kinetic reaction mechanisms for the diesel fuel and any oxygenated additives. This ignition calculation is carried out under conditions of pressure, temperature and fuel/air ratios that are characteristic of a diesel engine at the top of the piston stroke. The composition of the ignition products are then identified and their relative sooting tendencies are evaluated.

In order to carry out these model calculations, we must make several important simplifications to this problem. Since we do not have kinetic reaction 
mechanisms for all of the thousands of species present in conventional diesel fuel, we use n-heptane as a convenient substitute or surrogate for diesel fuel, using a kinetic reaction mechanism we developed ${ }^{33}$. N-heptane has frequently been used as a diesel surrogate ${ }^{34-38}$. The ignition properties of diesel fuel are described by its cetane rating in much the same way that the knocking behavior of gasoline in spark-ignition engines is characterized by its octane rating; nheptane has a cetane rating of 56 that is typical of ordinary diesel fuels, and its rich ignition products include most of the species found to lead to soot production.

In addition, we do not directly simulate the mixing of the injected fuel and hot air, instead using the results of mixing experiments and other modeling studies as described by Naber and Siebers ${ }^{39}$ as follows. The start of injection takes place about 10 degrees before Top Dead Center (TDC, the point at which the piston reaches the most compressed point in its cycle) in Dec's engine ${ }^{15}$, so the compressed air already has a relatively high temperature and pressure. We used temperature-dependent specific heats for the reactants and air, as well as the heats of vaporization of the fuel components, to mix cold fuel and hot air until the mixture reaches a temperature of about $770 \mathrm{~K}$, where the kinetic model indicates that significant reaction begins to occur. At this point, the kinetic simulations begin. The fuel/ air equivalence ratio is usually close to 3.0, although not every mixture will have exactly the same equivalence ratio, since the specific heats and heats of vaporization of n-heptane and each of the oxygenates we used 
are quite different. We have assumed that the combustion chamber pressure is approximately $10 \mathrm{MPa}$ at this point.

Once the ignition calculations begin, the simulations are performed in a constant pressure, spatially homogeneous environment, effectively decoupling the ignition process from the rest of the combustion chamber. In addition to the considerable simplification that these assumptions provide, these conditions are quite reasonable since the ignition of these fuel/air mixtures is quite rapid $(<1 \mathrm{~ms})$ in the diesel combustion chamber and there is little time for further exchange of heat or chemical species between the igniting mixture and the remainder of the combustion chamber.

In each model calculation, there is an initial induction period during which the temperature remains almost constant and the reactant concentrations decrease very slowly. After this short time delay, a very rapid ignition occurs during which the reactants are completely consumed, the temperature increases from about $770 \mathrm{~K}$ to about $1600 \mathrm{~K}$, and the products reach levels which remain nearly constant. This sequence is illustrated in Figure 3 for the case of neat nheptane fuel, showing the major reactants and products, with the ignition occurring at about $0.75 \mathrm{~ms}$. Note that under these very rich conditions, the $\mathrm{CO}$ product concentration is much larger than that of $\mathrm{CO}_{2}$.

The key to this analysis is the identification of those species in the rich ignition products which enhance soot production and those which compete with soot production. We rely largely on the soot modeling work of Frenklach ${ }^{22,23}$, which is based in turn on many careful and thorough experimental soot 

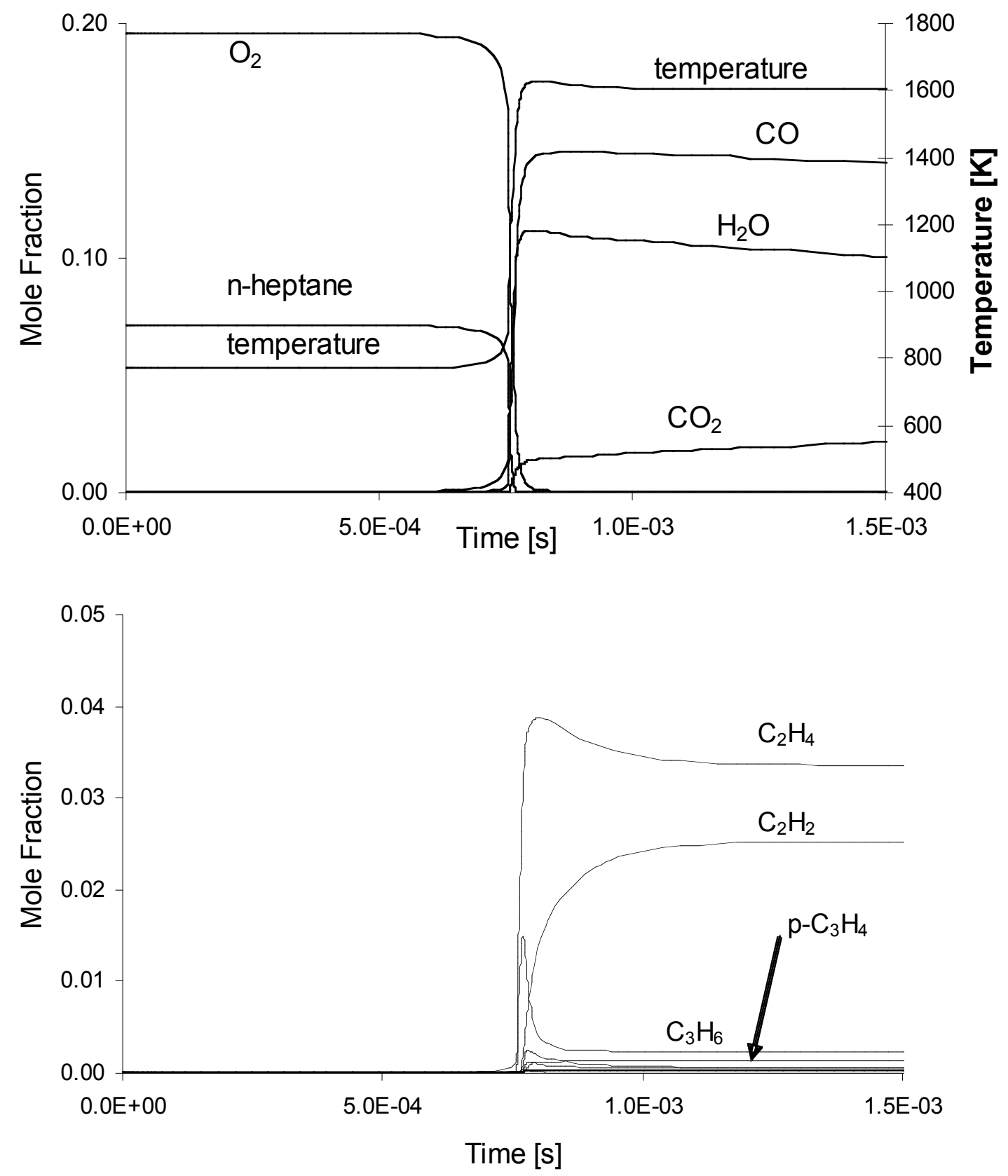

Figure 3. Computed temperature and major species mole fractions in fuelrich ignition of n-heptane/air at equivalence ratio of 3, $10 \mathrm{MPa}$ pressure, initial temperature of $767 \mathrm{~K}$. 
evolution studies, including particularly ${ }^{24-30}$. The overall picture of soot kinetics that emerges from these studies is that small aromatic and polycyclic aromatic hydrocarbons $(\mathrm{PAH})$ such as benzene, toluene, naphthalene, pyrene and styrene are produced from small unsaturated hydrocarbons such as acetylene, ethene, propene, allene, propyne, and cyclopentadiene, as well as resonantly stabilized hydrocarbon radical species such as propargyl, allyl, and cyclopentadienyl ${ }^{31}$. Subsequent reactions increase the size of the PAH species, leading eventually to visible soot, with acetylene being the most significant growth species ${ }^{23,25}$. Another key to understanding sooting chemistry is that oxygenated species including $\mathrm{CO}$ and $\mathrm{CO}_{2}$ do not participate in the kinetics of soot production.

Therefore we have used two methods to evaluate the relative sooting tendencies of rich ignition products under diesel conditions. The first method couples the PAH production mechanism of Appel, Bockhorn and Frenklach ${ }^{23}$ together with our own mechanisms for the fuel mixture ignition to predict levels of PAH species. This coupled mechanism approach has previously been employed successfully to predict soot production ${ }^{11-14}$. The second approach has been simply to sum all of the concentrations of known soot precursors (i.e., acetylene, benzene, ethene, toluene, propene and other unsaturated stable and resonantly stabilized hydrocarbons) that remain following the rich ignition event $^{9,10,21}$. Neither of these approaches can provide accurate values of total soot produced, and a great deal more experimental and kinetic modeling 
analysis will be necessary to provide this capability, but these techniques provide realistic estimates of relative soot production, which is suitable for the present study of soot reduction kinetics.

\section{Kinetic Reaction Mechanisms}

As noted above, n-heptane is used as the surrogate for diesel fuel. The reaction mechanism for $n$-heptane ${ }^{33}$ has been used widely in kinetic modeling studies as noted above, due in part to it being conveniently available on the $\mathrm{web}^{40}$. It includes more than 2400 elementary reactions with nearly 600 chemical species, including the low temperature, alkyl peroxy submechanisms that provide early heat release and advance the timing of the eventual hot ignition.

Most of the oxygenates used in this study had detailed kinetic reaction mechanisms already available which were used without further modification, including mechanisms for methanol ${ }^{41}$, ethanol ${ }^{42}$, dimethyl ether ${ }^{43-46}$, dimethyl carbonate $^{47}$, and methyl butanoate ${ }^{48}$. However, new kinetic mechanisms were also developed for dimethoxy methane (DMM) and two other considerably more complex oxygenated species, tri-propylene glycol methyl ether (TPGME), and dibutyl maleate (DBM). Both TPGME and DBM were recommended ${ }^{4}$ as oxygenated hydrocarbons with substantial $\mathrm{O}$ atom loading $(4$ oxygen atoms per molecule) which have satisfactory fuel properties such as diesel fuel solubility and are relatively economical to produce. The structures of all of the oxygenates used in this study are summarized in Figure 4. 


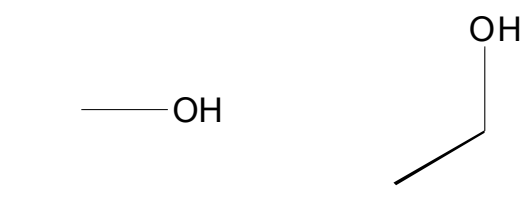

methanol ethanol

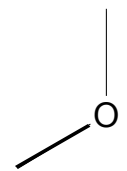

dimethylether

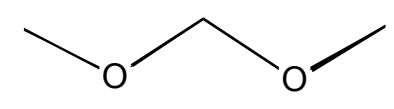

dimethoxymethane

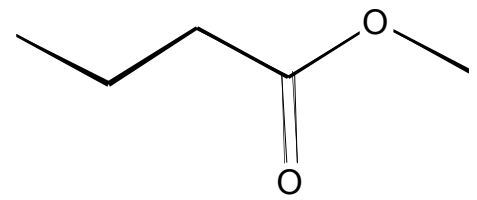

methylbutanoate

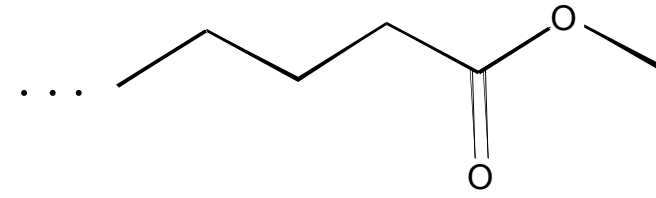

biodiesel<smiles>COC(C)COC(C)COC(C)CO</smiles>

tripropylene-gycol-monomethylether<smiles>COC(=O)OC</smiles>

dimethylcarbonate<smiles>CCCCOC(=O)/C=C/C(=O)OCCCC</smiles>

dibutylmaleate

Figure 4. Chemical structures of oxygenated species used in model calculations.

The methyl butanoate was selected for analysis as a convenient substitute for the very large methyl ester molecules that are typical of so-called biodiesel fuels. This similarity is shown in Figure 4, showing that both molecules have the 
same oxygenated section, but biodiesel molecules have a much larger hydrocarbon segment, often with as many as 16-18 C atoms. As described below, the computed results for the methyl ester structure were sufficiently interesting and potentially important that we chose to also consider the kinetics of dimethyl carbonate, also shown in Fig. 4, which, along with DBM, also has an oxygenated structure similar to the biodiesel fuels.

Detailed chemical kinetic reaction mechanisms were developed for DBM and TPGME. As in our previous mechanism developments ${ }^{47}$, thermodynamic parameters were estimated using quantum chemistry methods and group additivity ${ }^{49-51}$. For most species the enthalpy of formation was computed using CBS-Q methods with geometries optimized at the B3LYP/6-31G9(d,p) level following Bozzelli ${ }^{52}$, and other details of the techniques are described by Glaude et al. ${ }^{47}$. All of these kinetic mechanisms are available on our web page ${ }^{40}$.

\section{Computational Results}

The baseline calculation for this study is the ignition of n-heptane and air, at an equivalence ratio of about 3.0, a fixed pressure of $10 \mathrm{MPa}$, and an initial temperature of $767 \mathrm{~K}$, as described above and shown in Figure 3. Because this mixture is so fuel-rich, the product temperature of $1600 \mathrm{~K}$ is considerably below the adiabatic flame temperature ( $>2200 \mathrm{~K})$ of the corresponding stoichiometric $n$ heptane/air mixture. The products and temperature rapidly approach a quasi- 
equilibrium in which the major products are $\mathrm{CO}$ and $\mathrm{H}_{2} \mathrm{O}$, with smaller amounts of $\mathrm{CO}_{2}, \mathrm{C}_{2} \mathrm{H}_{4}$ and $\mathrm{C}_{2} \mathrm{H}_{2}$. Very little $\mathrm{CO}_{2}$ is produced in this very rich mixture. and it is important to note that all of the fuel and initial $\mathrm{O}_{2}$ is entirely consumed. The major soot precursors, ethene, acetylene, propyne and propene, for this baseline mixture are shown in Figure 3. The total amount of carbon present in these unsaturated products comprises approximately $44 \%$ of the total carbon present initially in the $\mathrm{n}$-heptane fuel. These quasi-equilibrium products then produce small aromatic species, including benzene, naphthalene and styrene, and eventually soot, as described by Appel et al. ${ }^{23}$.

We then repeated this baseline calculation, gradually replacing n-heptane fuel with varying amounts of the oxygenated hydrocarbon species shown in Figure 3. For each of these oxygenated species, as n-heptane is replaced by the oxygenate, the fraction of carbon remaining in the form of soot precursors in the rich ignition products decreases, being replaced by increased levels of $\mathrm{CO}$ and $\mathrm{CO}_{2}$. For example, the product concentrations for a fuel mixture consisting of a nearly equimolar mixture of $\mathrm{n}$-heptane and methanol ( $0.4 \mathrm{n}$-heptane +0.6 methanol) are shown in Figure 5. The ignition time is very slightly longer than the baseline but the overall chemical features of the two ignitions are quite similar. However, important changes are the increase in the $\mathrm{CO}_{2} / \mathrm{CO}$ ratio in the 

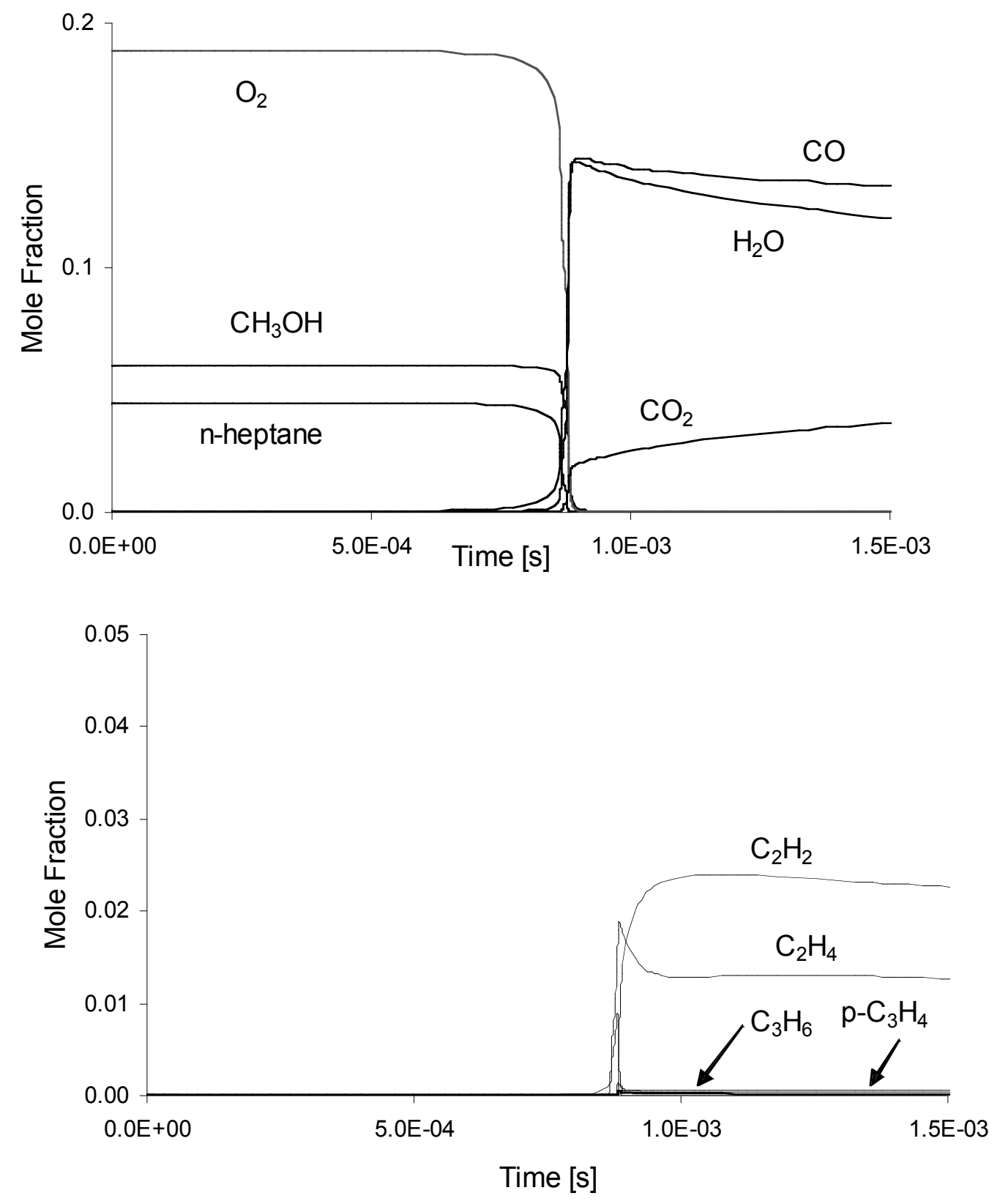

Figure 5. Computed major species mole fractions in fuel-rich ignition of n-heptane/methanol / air at $10 \mathrm{MPa}$ pressure, initial temperature of 767K. products, and the reductions in the total carbon in the unsaturated species in the products. The reduction in ethene is quite large while the acetylene is only slightly reduced, and the overall reduction in this carbon soot precursor pool is 
from $44 \%$ in the baseline case to about $28 \%$ in this mixed fuel case. The fraction of oxygen in the two-component fuel is $15 \%$.

Further replacement of $\mathrm{n}$-heptane by more methanol continues the displacement of soot precursors in these products, until the soot precursor levels become very small, where oxygen has reached about $30 \%$ of the total mass of the mixed fuel of n-heptane and methanol, as shown in Figure 6. At this point, the fuel consists of close to $17 \%$ n-heptane and $83 \%$ methanol on a molar basis, or:

Fuel composition at soot elimination $=1 \mathrm{C}_{7} \mathrm{H}_{16}+5 \mathrm{CH}_{3} \mathrm{OH}$

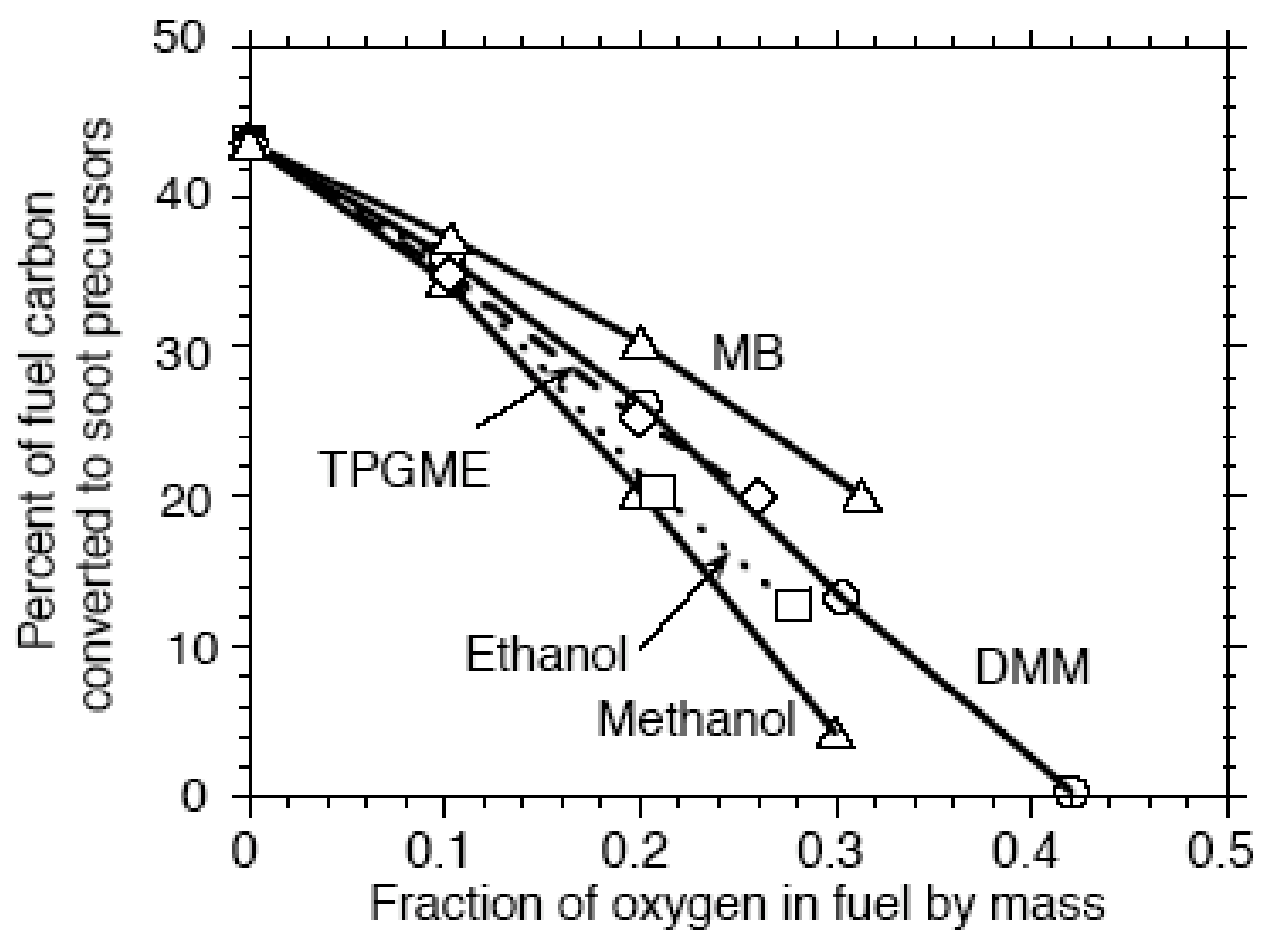

Figure 6. Computed reductions in soot precursor concentrations with addition of selected oxygenated species. Abbreviations for fuels are identified in the text. 
Note that in the initial fuel mixture at this condition, $42 \%$ (i.e., 5 of 12 ) of the initial carbon atoms are already bonded to oxygen in the oxygenate (i.e., methanol) molecules. Under these conditions it is clearly inappropriate to refer to the methanol as an "additive", since it is the major component in the fuel on a molar basis and more than $60 \%$ of the total fuel mass.

Further insight is provided by noting that, since all of these mixtures are assumed to include the same amount of entrained air, the overall equivalence ratio, including the oxygen atoms in the methanol, has been reduced from 3.0 to about 2.2 by the addition of this much methanol.

The influence of mixture equivalence ratio at the time of rich ignition on sooting is complex. In the present analysis, the equivalence ratio at the time of ignition is varied by inclusion of different amounts of oxygenated species, while the amount of entrained air is held fixed. In contrast, Siebers and Higgins 53 systematically varied the amount of entrained air and therefore the equivalence ratio at the time of diesel ignition by varying the injection pressure of diesel fuel into a constant volume combustion bomb and the corresponding variation in flame lift-off length. Siebers and Higgins found the amount of soot production to be quite sensitive to the equivalence ratio. They also observed that soot production became negligible when enough air was entrained to produce a local equivalence ratio of approximately 2 at the time and location of ignition. Comparison of this result with the present kinetic modeling results shows that providing additional oxygen for the ignition, either through extra entrained air or through its presence within the fuel molecules, reduces the amount of carbon in those species available for producing soot. This suggests that the critical 
parameter in soot production is the amount of available carbon once all of the oxygen has been consumed, and there are at least two ways to influence the size of that post-ignition carbon pool.

We repeated the same type of rich ignition calculations using other oxygenated species including ethanol, dimethyl ether, dimethoxy methane, and methyl butanoate. These model calculations produced results very similar to those for methanol, and the resulting decreases in soot precursor concentrations in the ignition products are summarized in Figure 6. It is important to note that all of these nearly straight lines are quite similar to the results from the experimental diesel engine studies summarized in Figure 1.

The major soot precursors remaining in the ignition products of all of these mixtures are acetylene, ethene, propene, and other $C_{3}$ compounds including propargyl radicals $\left(\mathrm{C}_{3} \mathrm{H}_{3}\right)$, as shown in Figures 3 and 5. Nearly all of the oxygen appears as $\mathrm{CO}$ and $\mathrm{H}_{2} \mathrm{O}$, with quite small amounts of $\mathrm{CO}_{2}$. Water is produced via $\mathrm{H}$ atom abstraction reactions from the fuel by $\mathrm{OH}$, and water production is responsible for most of the heat release leading to ignition. As the mass fraction of oxygen in the fuel mixture increases, a larger fraction of the total amount of carbon in the fuel is converted to $\mathrm{CO}$ and $\mathrm{CO}_{2}$ and a smaller amount of carbon is present as soot precursors. When the PAH formation kinetic model of Appel et al. ${ }^{23}$ is incorporated into our model calculations, the concentrations of PAH's in the products are correspondingly reduced steadily as the oxygen 
content of the fuel increases, reaching near-zero levels when the oxygen content in the fuel reaches approximately $30 \%$.

Careful examination of the kinetic pathways associated with the ignition of these oxygenates showed that nearly all of the oxygen atoms initially present in the oxygenates react directly to produce $\mathrm{CO}$; the strong $\mathrm{CO}$ bond remains intact during the ignition, so the $\mathrm{C}$ atom in this bond never becomes available for soot production. When methanol is the oxygenate, it is consumed ${ }^{41}$ primarily via a very linear reaction path:

$$
\mathrm{CH}_{3} \mathrm{OH} \rightarrow \mathrm{H}_{2} \mathrm{C} \bullet \mathrm{OH} \rightarrow \mathrm{CH}_{2} \mathrm{O} \rightarrow \mathrm{HC} \bullet \mathrm{O} \rightarrow \mathrm{CO}
$$

In dimethoxy methane and di-methyl ether, each oxygen atom is initially bonded to two $\mathrm{C}$ atoms, but although one $\mathrm{C}-\mathrm{O}$ bond is broken during its combustion, the $\mathrm{O}$ atom remains bonded to another $\mathrm{C}$ atom. Specifically, in the case of DME, the dominant reaction pathway is $\mathrm{H}$ atom abstraction to produce:

$$
\mathrm{CH}_{3} \mathrm{OCH}_{3} \rightarrow \mathrm{H}_{2} \mathrm{C} \bullet \mathrm{OCH}_{3} \rightarrow \mathrm{CH}_{2} \mathrm{O}+\mathrm{CH}_{3}
$$

which leaves the $\mathrm{O}$ atom bonded to one $\mathrm{C}$ atom. As in methanol oxidation, formaldehyde reacts directly via HCO to produce CO. Similarly, DMM reacts primarily by $\mathrm{H}$ atom abstraction:

$$
\mathrm{CH}_{3} \mathrm{O}\left(\mathrm{CH}_{2}\right) \mathrm{OCH}_{3} \rightarrow \mathrm{H}_{2} \mathrm{C} \bullet \mathrm{O}\left(\mathrm{CH}_{2}\right) \mathrm{OCH}_{3} \rightarrow \mathrm{CH}_{2} \mathrm{O}+\mathrm{H}_{2} \mathrm{C} \bullet \mathrm{OCH}_{3}
$$

followed by $\quad \mathrm{H}_{2} \mathrm{C} \cdot \mathrm{OCH}_{3} \rightarrow \mathrm{CH}_{2} \mathrm{O}+\mathrm{CH}_{3}$

with each $\mathrm{O}$ atom remaining bonded to one $\mathrm{C}$ atom, leading to $\mathrm{CO}$ formation.

The same analysis for TPGME is somewhat more complex, since the molecule is much larger and there are many possible $\mathrm{H}$ atoms that can be 
abstracted to initiate its oxidation. One of the 11 possible $\mathrm{H}$ atom abstraction steps can be used as an illustration as shown in Figure 7. In this case, one of the<smiles>COC(C)COC(C)COC(C)CO</smiles>

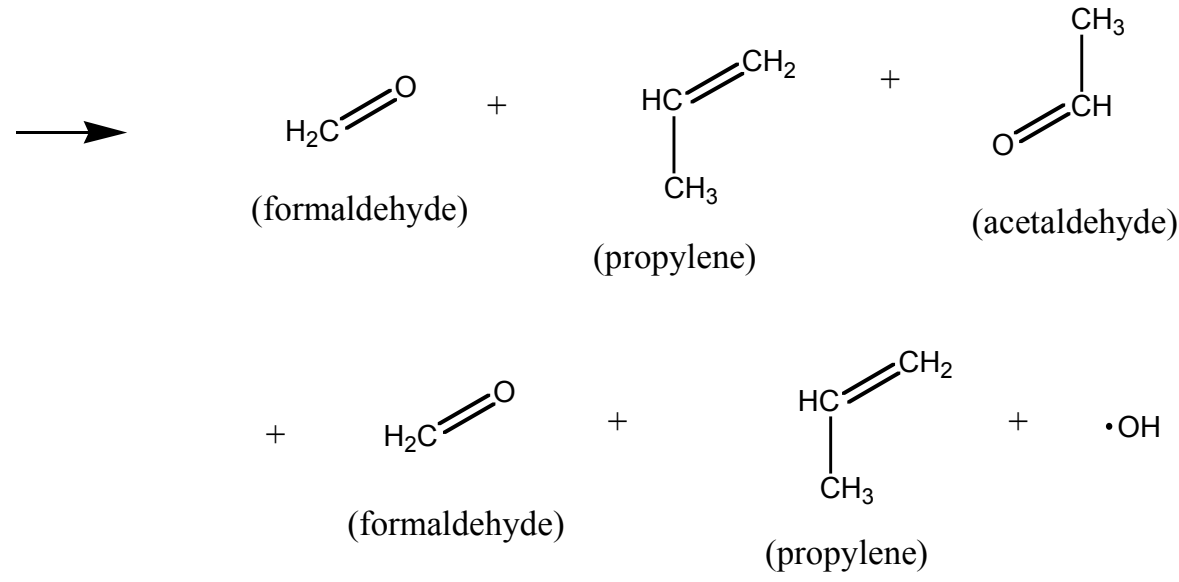

Figure 7. Schematic diagram of overall products of consumption of TPGME.

$\mathrm{H}$ atoms from the $\mathrm{CH}_{3}$ group at the end of the molecule has been abstracted, leaving a large radical species that, under the present ignition conditions, decomposes rapidly via a series of $\beta$-scission paths. The ultimate set of products is shown as two formaldehyde molecules, two propylene molecules, one molecule of acetaldehyde and an $\mathrm{OH}$ radical. In this example, three of the four $\mathrm{O}$ atoms in TPGME remain bonded to carbon atoms, and these carbon atoms are therefore eliminated from the pool of possible soot precursor species. When the same analysis is repeated for the other 10 radicals that can be produced from $\mathrm{H}$ 
atom abstraction from TPGME, a very similar group of products is created, in which one or two propylene molecules are produced and either 3 or $4 \mathrm{O}$ atoms remain bonded to $\mathrm{C}$ atoms. None of these reaction paths produces two $\mathrm{O}$ atoms bonded to a single $\mathrm{C}$ atom, so the overall result is an efficient usage of the $\mathrm{O}$ atoms initially present in the TPGME in preventing those $\mathrm{C}$ atoms from contributing to the pool of available soot precursor species. The important feature is the distribution of $\mathrm{O}$ atoms in the TPGME molecule, so that each $\mathrm{O}$ atom leads to a $\mathrm{CO}$ molecule in the ignition products.

For all of the oxygenates above, almost every $\mathrm{O}$ atom in the oxygenate removes one $\mathrm{C}$ atom from the pool of species that can produce soot. In each case, the $\mathrm{O}$ atom is initially bound to a $\mathrm{C}$ atom, and this bond is not subsequently broken. These oxygenated species displace $\mathrm{C}$ atoms in the diesel fuel with $\mathrm{C}$ atoms that are bonded to $\mathrm{O}$ atoms. This displacement exchanges $\mathrm{C}$ atoms that $\underline{\text { can }}$ produce soot with $\mathrm{C}$ atoms that, since they are bonded to $\mathrm{O}$ atoms, cannot contribute to soot production. Each of these oxygenated species is equally effective, per $\mathrm{O}$ atom in the additive, because each $\mathrm{O}$ atom removes one $\mathrm{C}$ atom from the soot producing pool of species. The specific structure of the oxygenate has little impact on this process, providing that the structure retains the ability of each $\mathrm{O}$ atom to remove one $\mathrm{C}$ atom from the soot producing pool of species.

All of the oxygenates shown in Figure 6 reduce the levels of soot precursors and at sufficiently high concentrations will eliminate soot emissions. From the results in Figure 6, most of these oxygenates are quite similar in their ability to reduce soot emissions. However, the curve for methyl butanoate (MB) suggests that its inhibiting power is slightly less than the other oxygenates in its ability to reduce soot precursor formation. This result could be due to errors in 
the development of the kinetic mechanism, for which very little experimental data are available for mechanism validation. MB had been chosen for attention because of its similarity to biodiesel fuels, so it is important to determine if this trend is significant and reflects real kinetic features, and if so, what kinetic factors are responsible for the computed behavior.

\section{Ester Structures}

There is considerable interest in the use of so-called biodiesel fuels, fuels which are derived from a variety of vegetable oils and have combustion properties similar to conventional diesel fuels. Such fuels are attractive since they represent a type of renewable fuel, and the fact that they include oxygen atoms gives them the potential to also reduce soot emissions when used in diesel fuels. Biodiesel fuels are usually produced from vegetable oils by esterification, which results in a characteristic structure with two $\mathrm{O}$ atoms located at the end of a long hydrocarbon chain. For most vegetable oils of interest ${ }^{54}$, the hydrocarbon chain contains 16 to 20 carbon atoms which can include several unsaturated segments, with a characteristic methyl ester group at one end shown in Figure 4.

We had chosen MB for kinetic modeling study in order to reduce the computational complexity of the actual bio-diesel fuels, with its butyl radical group replacing the $\mathrm{C}_{16}-\mathrm{C}_{18}$ radical chain. This makes it possible to investigate the features of the methyl ester group without the computational complexity of the larger hydrocarbon group.

As shown in Figure 4, the main feature of this group is that the two $\mathrm{O}$ atoms are both bonded to a single $\mathrm{C}$ atom. The double $\mathrm{C}=\mathrm{O}$ bond is difficult to 
break, and the important question is whether or not the other $\mathrm{O}$ atom remains bonded to the same $\mathrm{C}$ atom. Using conventional rules for kinetic rates, we found that during combustion of the $\mathrm{MB}$, approximately half of the reaction pathways resulted in both $\mathrm{O}$ atoms remaining bonded to the single $\mathrm{C}$ atom. As a result, $\mathrm{CO}_{2}$ was produced directly, and the two $\mathrm{O}$ atoms together removed only one $\mathrm{C}$ atom from the pool of reactive hydrocarbons that could produce soot.

To examine this effect in greater detail, two additional oxygenated species were selected for further consideration, including dimethyl carbonate (DMC) and a larger species, di-butyl maleate (DBM), that had been selected by the same committee that had recommended TPGME for further study ${ }^{4}$. These structures are shown in Figure 4; both dibutyl maleate and dimethyl carbonate are characterized by variations of the same ester structure as in MB. Dimethyl carbonate was selected for two reasons; first, its high weight fraction of oxygen offers the possibility that it could have a strong soot inhibition effect on diesel combustion, and second, it provides a relatively clear way to examine the role of the ester group in determining the kinetic fate of oxygen atoms in these oxygenated species. DBM was included because it was a more realistic practical diesel fuel component which had the same ester structure as MB and DMC but had a higher $\mathrm{O}$ atom content than the other oxygenates with the same structure.

In Figure 8 the relative effectiveness of these new oxygenated species on soot precursor reduction is summarized, together with the previous results for the cases with methanol and methyl butanoate as the oxygenates. These results show that all three oxygenates that have the characteristic ester group are less effective at reducing soot precursor levels than the oxygenates without the ester 
structure, on the basis of effect per unit oxygen atom in the fuel. The DBM is even less effective than methyl butanoate or dimethyl carbonate. In each of these

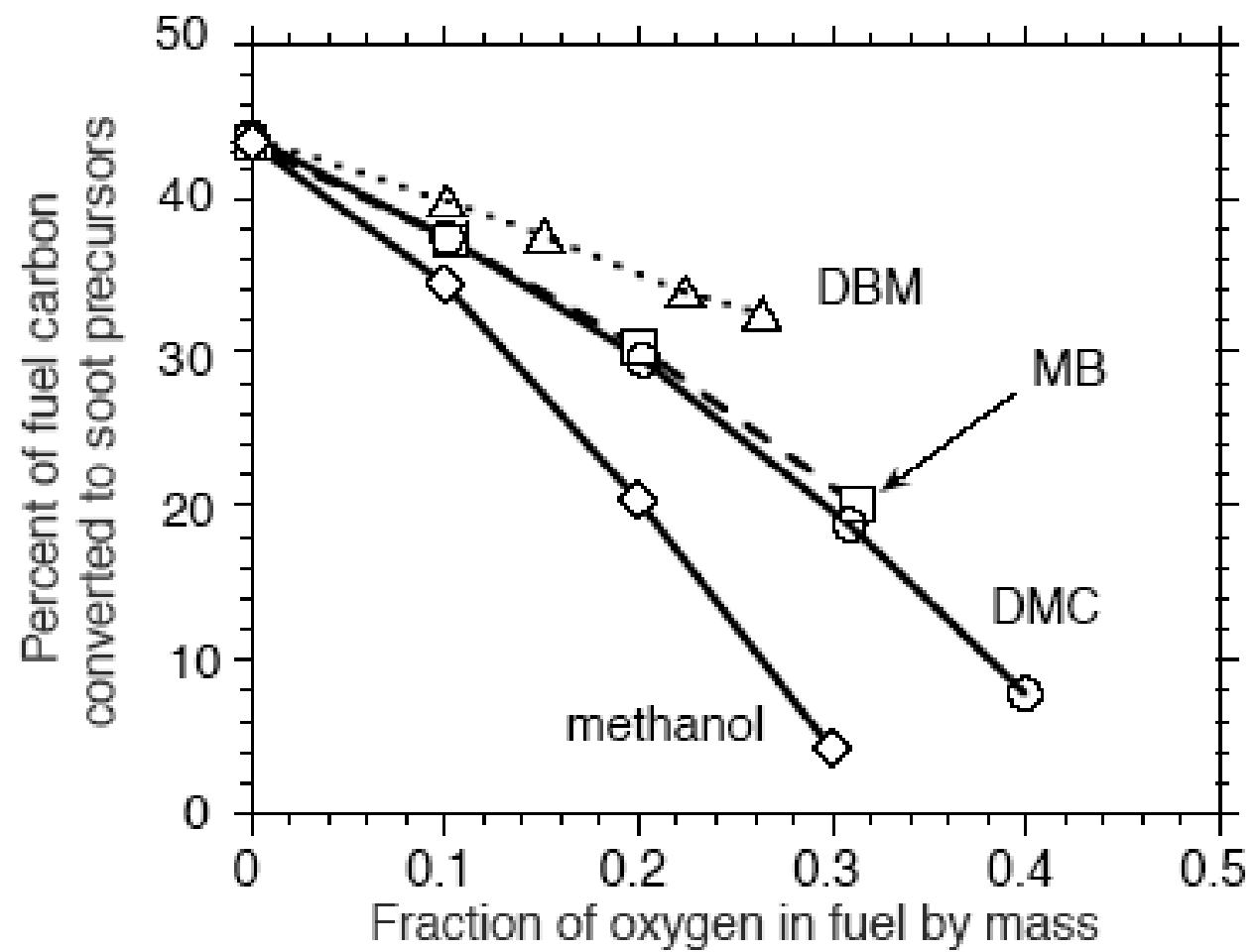

Figure 8. Computed reductions in soot precursor concentrations with addition of oxygenated species containing ester structure.

cases, the kinetic modeling shows that the particular locations and bond structures involving the $\mathrm{O}$ atoms lead to a considerable fraction of direct $\mathrm{CO}_{2}$ formation from the oxygenated fuel species. This means that not every $\mathrm{O}$ atom in these compounds is able to eliminate a carbon atom from the soot precursor pool, resulting in a higher fraction of the remaining carbon atoms available to produce soot. 
Combustion of these oxygenates (i.e., those containing the ester group) produces considerable amounts of the alkoxy formyl radical, $\mathrm{R} \mathrm{O} \mathrm{C} \bullet=\mathrm{O}$, where $\mathrm{R}$ is an alkyl radical. In the case of DMC as the oxygenated species, in which $\mathrm{R}$ is the methyl radical, approximately $78 \%$ of the methoxy formyl radical decomposes to produce $\mathrm{CO}_{2}$, with only $22 \%$ producing $\mathrm{CO}+\mathrm{CH}_{3} \mathrm{O}$. In the case of DBM as the oxygenated species, nearly $90 \%$ of the analogous n-butoxy formyl radical produces $\mathrm{CO}_{2}$. Glaude et al. ${ }^{47}$, McCunn et al. ${ }^{55}$ and Good and Francisco ${ }^{56}$ have examined the methyl formyl decomposition reaction, using CBS-Q and CCSD(T) methods at the B3LYP level, and all three studies agreed that the energy barrier to the $\mathrm{CH}_{3}+\mathrm{CO}_{2}$ product channel is about $14.7 \mathrm{kcal} / \mathrm{mol}$, while the barrier to the $\mathrm{CH}_{3} \mathrm{O}+\mathrm{CO}$ products is more than $22 \mathrm{kcal} / \mathrm{mol}$, explaining why the $\mathrm{CO}_{2}$ channel would be expected to dominate.

\section{Discussion}

Reduction of soot production by oxygenated species is a recent development, and relatively few experimental tests have appeared to date that can be used for confirmation of the mechanism presented here. Based on preliminary model predictions by the present authors, Buchholz et al. ${ }^{10}$ used radiocarbon labeling of different $\mathrm{C}$ atoms in dibutyl maleate (DBM) to show experimentally that a significant fraction of the $\mathrm{O}$ atoms in $\mathrm{DBM}$ were converted directly into $\mathrm{CO}_{2}$. They selectively labeled the three distinct carbon atoms shown in Figure 9 in 
successive experiments and used Accelerator Mass Spectrometry (AMS) to detect ${ }^{14} \mathrm{C}$ in the $\mathrm{CO}_{2}$ exhaust gases, in the soot that was collected, and in the surface deposits that were produced. Their analysis showed

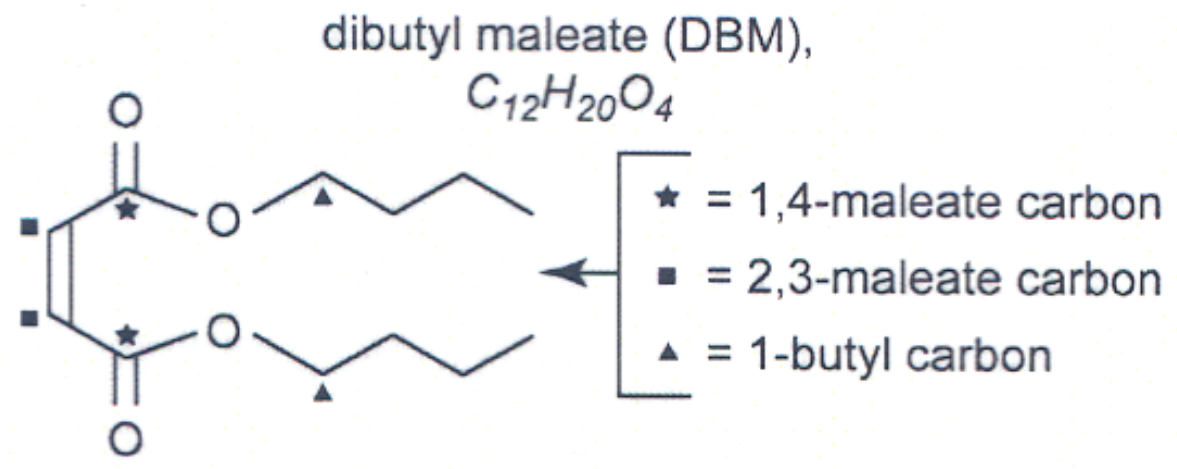

Figure 9. Schematic diagram of DBM, showing sites where $C$ atoms were labeled with ${ }^{14} \mathrm{C}$ for accelerator mass spectroscopy.

that the bonds between the 1-butyl groups and the adjacent $\mathrm{O}$ atoms were broken approximately $90 \%$ of the time and that the carbon atoms bonded to two $\mathrm{O}$ atoms in DBM remain bonded through the rich ignition period, resulting in direct production of $\mathrm{CO}_{2}$.

Szybist and Boehman ${ }^{57}$ have carried out compression-ignition studies in a CFR test engine, using as fuels both n-heptane and methyl decanoate, a monomethyl ester with a saturated, straight-chain alkyl radical with 10 carbon atoms. Their experiments measured heat release rates, gas temperatures, and exhaust gas composition using FTIR spectroscopy over a range of compression ratios leading to actual ignition. One important observation of their study was 
the production of $\mathrm{CO}_{2}$ at very early stages of combustion associated with fuel decomposition, before any significant heat release had occurred. Early production of $\mathrm{CO}_{2}$ was observed only when the fuel was methyl decanoate, and no corresponding $\mathrm{CO}_{2}$ production was observed when the fuel was n-heptane.

Their conclusion was that the $\mathrm{CO}_{2}$ was a direct product of the methyl ester group in their methyl decanoate, consistent with the present kinetic modeling analysis. Mueller et al. ${ }^{9}$ directly compared the soot reduction effectiveness of DBM and TPGME in a diesel engine and in a constant volume combustion bomb. They found, in both experimental configurations, that TPGME was significantly more effective than DBM in reducing soot levels, which were measured using spatially integrated natural luminosity and line-of-sight laser extinction techniques. Experimental engine studies by Zannis et al. ${ }^{59}$ also found that different oxygenated species structures produced different soot reduction efficiencies. The results of all of these experimental engine studies are consistent with the present description of how $\mathrm{O}$ atoms in the oxygenated species are used to suppress soot production.

The most obvious test of the present mechanism is that it predicts accurately the rate of soot suppression a the oxygen level in the fuel increases and the oxygen levels required to eliminate soot entirely. This is shown by comparing the experimental results in Figure 1 and the modeling predictions from Figure 6. Although this is an integrated result, it also is a widely observed phenomenon, and the fact that the same behavior is observed for so many 
oxygenated fuel components and that the model reproduces that observation as well makes this a convincing test of the model.

We calculated the chemical equilibrium compositions for the mixtures summarized in Figures 3 and 5, with n-heptane and an n-heptane/methanol mixture as the fuels. We found that the major equilibrium components in each case consisted of $\mathrm{CO}, \mathrm{H}_{2}$ and $\mathrm{CH}_{4}$, in addition to the $\mathrm{N}_{2}$ present in the air. The other species in Figures 3 and 5, including $\mathrm{H}_{2} \mathrm{O}, \mathrm{CO}_{2}, \mathrm{C}_{2} \mathrm{H}_{2}$ and $\mathrm{C}_{2} \mathrm{H}_{4}$ all are present in the equilibrium mixtures at levels of less than $1 \%$ mole fraction, indicating that the products computed kinetically are far from equilibrium. The product compositions in Figures 3 and 5 therefore represent an arrested kinetic process that had been proceeding to oxidation products. This permits us to summarize the evolution of the reactants through the ignition period.

Stoichiometric oxidation of n-heptane ${ }^{33}$ occurs primarily by means of $\mathrm{H}$ atom abstraction, followed by decomposition of the resulting heptyl radicals; the principal next product is ethene as the long n-alkane chain is chopped into $\mathrm{C}_{2} \mathrm{H}_{4}$ blocks. Ethene is consumed by radicals to produce vinyl radicals $\left(\mathrm{C}_{2} \mathrm{H}_{3}\right)$ which then decomposes to produce acetylene. Subsequent oxidation of acetylene leads to $\mathrm{CO}$ and $\mathrm{CO}_{2}$. In the diesel rich ignition calculations, it is clear that the computed reactions were proceeding normally towards combustion products when the limitations of the very fuel-rich environment quenched or interrupted the process. Because the rich conditions provide less heat release than stoichiometric conditions, the system cannot produce enough radicals to 
complete the oxidation process. Those radicals that are produced convert as much ethene as possible to acetylene, but it is clear from Figure 3 that this conversion is far from complete. $\mathrm{OH}$ radicals convert $\mathrm{CO}$ to $\mathrm{CO}_{2}$ and produce $\mathrm{H}_{2} \mathrm{O}$ from $\mathrm{H}$ atom abstraction reactions with the fuel, producing far more $\mathrm{CO}_{2}$ and $\mathrm{H}_{2} \mathrm{O}$ than is present at equilibrium conditions at these temperatures, in an interesting example of a situation in which the dynamic, kinetics processes actually take the chemical system farther from equilibrium.

Kinetic production of superequilibrium $\mathrm{CO}_{2}$ levels is a very important feature of this rich ignition and the production of soot in the diesel. At these rich conditions, the equilibrium composition contains none of the species normally associated with aromatic formation reaction pathways and soot production, particularly very low levels of ethene and acetylene. At equilibrium, all of the available $\mathrm{O}$ atoms are present in the form of $\mathrm{CO}$. However, during the kinetically controlled ignition, the $\mathrm{OH}$ radicals that might have facilitated the equilibrium have instead oxidized $\mathrm{CO}$ to $\mathrm{CO}_{2}$ and produced $\mathrm{H}_{2} \mathrm{O}$. The remaining $\mathrm{C}$ and $\mathrm{H}$ have no way to avoid remaining in the form of soot precursors, because the kinetic system has achieved a composition that is locally stable although far from true equilibrium. When $\mathrm{O}$ atoms in the oxygenated additive produce $\mathrm{CO}_{2}$ immediately, because of the unfortunate placement of $\mathrm{O}$ atoms within those molecules, the imbalance towards $\mathrm{CO}_{2}$ in the products is 
even more pronounced and the kinetic system remains far from the equilibrium that otherwise would have limited sooting.

When the oxygenate, methanol in this example, is added, some additional radicals are produced because the overall mixture, including the oxygenate, is slightly less rich (or closer to stoichiometric). The enhanced radical population converts more ethene to acetylene and more $\mathrm{CO}$ to $\mathrm{CO}_{2}$, both of which are reflected in the comparisons between Figure 3 and Figure 5. In addition, there is less ethene to convert to acetylene, since a great deal of the n-heptane has been displaced by methanol. As more oxygenate is added and the overall mixture becomes less fuel-rich, the steadily increasing radical pool is able to convert more intermediate species, particularly those which contribute to soot production, to non-sooting products. Eventually, as the overall equivalence ratio reaches 2.0, there are enough radical species to not only consume the ethene, but also the subsequent intermediate acetylene.

This type of analysis suggests how soot suppression is accomplished for the cases in which extra air is entrained ${ }^{53}$. Entrainment provides additional molecular oxygen, which can react rapidly with radical species such as vinyl and produce $\mathrm{HO}_{2}$ radicals which then can abstract $\mathrm{H}$ atoms from the fuel or react further with the unsaturated species. Thus there are many reaction pathways that can be accelerated by the addition of more molecular oxygen.

Thus both increasing $\mathrm{O}_{2}$ by air entrainment and addition of oxygenates activate reaction pathways that advance the kinetic system towards final products and reduce the concentrations of those intermediates which lead to soot 
production. Details of the two reaction pathways are different, but the result is the same.

The present analysis also suggests that different fuels will each have their own characteristic types of intermediate products with their own sooting properties. The present analysis has used n-heptane as the surrogate for diesel fuel, and the resulting soot precursors are predominantly ethene and its product acetylene. Branched alkanes will produce unsaturated intermediates that contain more branched species than in the present simulations, such as isobutene, in addition to acetylene and ethene. Cyclic alkanes and alkenes, and aromatic fuels will each produce soot precursor species that are characteristic intermediate products of their oxygen-deprived or fuel-rich ignition. This provides the system "memory" of its original composition so the sooting tendencies of each original fuel will vary as the distribution of the ignition products vary.

A particularly important subject for future study is the role of aromatic hydrocarbons in the fuel on the fuel-rich diesel ignition and the production of soot precursors. The soot modeling work of Frenklach ${ }^{22.23}$, as well as a large body of experimental work, has established that production of aromatic and polycyclic aromatic species is a major step towards soot production, and the production of specific precursors to aromatic species formation has been a central element in the present study. As shown in Figures 3 and 5, our kinetic model predicts that all of the original fuel is consumed during the rich ignition, but similar simulation of fuel-rich ignition of aromatic fuels under diesel conditions has not yet been addressed. Since the specific hydrocarbon fragments in the ignition products are influenced by the structure of the fuel, the 
composition of the soot precursors in the case of aromatic fuels may be quite different from the present species, and this will be addressed in future work.

Finally, it should be noted that the present analysis applies to the unique case of premixed ignition, which proceeds along a sequential reaction pathway. The same conclusions do not apply to non-premixed systems such as diffusion flames, which are kinetically much more complex than the present systems. For

example, McNesby et al. ${ }^{12}$ recently discussed soot formation in an opposed flow ethene/ air flame, adding ethanol to the air stream and alternatively to the fuel stream, observing quite different responses of the sooting flame in these two cases. This creates regions in which reaction pathways are important that do not contribute to the premixed diesel environment.

\section{Summary}

Diesel engine chemistry has been primarily an experimental subject, but the phenomenological model of Dec ${ }^{15-21}$ has provided a framework within which focused computational studies can provide valuable insights. The present kinetic modeling analysis fits conveniently into Dec's framework, connecting the fuel vaporization and air entrainment processes with the soot growth period.

The key feature of the present study is that C-O moieties imbedded in the oxygenated species effectively displace carbon in the original diesel fuel; the $\mathrm{C}-\mathrm{O}$ bond survives the fuel-rich ignition intact, so there is less carbon available to make soot in the oxygen-depleted post-ignition environment. Soot reduction has generally been measured experimentally as a reduction in soot emissions per $\mathrm{O}$ 
atom included in the reactant molecules. For some years it was believed $3,54,58$ that reduction of soot depended only on the amount of oxygen added to the diesel and was not affected by the specific oxygenate type. However, recent experimental and kinetic modeling analysis has shown ${ }^{2,9-11,59}$ that there are some oxygenated species that use their oxygen atoms less efficiently than others. The present work attributes these effects to details in the ways the oxygen atoms are present in the oxygenated additive species, particularly in the case of ester species in which two $\mathrm{O}$ atoms are initially bonded to single $\mathrm{C}$ atoms. When these $\mathrm{CO}_{2}$ moieties result in direct production of $\mathrm{CO}_{2}$ molecules, the oxygen initially present in the oxygenated hydrocarbon additives is therefore less efficient in eliminating $\mathrm{C}$ atoms from the product pool of species that can subsequently make soot.

\section{Acknowledgments}

The authors appreciate receiving information in advance of publication from Prof. Andre Boehman of The Pennsylvania State University and Prof. Laurie Butler of the University of Chicago. This work was supported by the U.S. Department of Energy, Office of FreedomCAR and Vehicle Technologies, and was performed under the auspices of the U.S. Department of Energy by the University of California, Lawrence Livermore National Laboratory under Contract No. W-7405-Eng-48. 


\section{References}

1. Federal Register 66, No. 12 (2001). 5005. Available from:

http:/ / www.epa.gov/fedrgstr/EPA-AIR/2001/January/Day-18-a01a.pdf.

2. Ban, H., Farrell, J.T., Hotta, Y., Nakakita, K., Takasu, S., and Weissman, W., “Effect of Hydrocarbon Molecular Structure in Diesel Fuel on In-Cylinder Soot Formation and Exhaust Emissions", Society of Automotive Engineers paper SAE 2003-01-1914 (2003).

3. Miyamoto, N., Ogawa, H., Nurun, N.M., Obata, K., and Arima, T., Smokeless, Low NOx, High Thermal Efficiency, and Low Noise Diesel Combustion with Oxygenated Agents as Main Fuel", Society of Automotive Engineers paper SAE 980506 (1998).

4. Gonzalez, M.A., Piel, W., Asmus, T., Clark, W., Garbak, J., Liney, E., Natarajan, M., Naegeli, D.W., Yost, D., Frame, E., and Wallace, J.P., “Oxygenates Screening for Advanced Petroleum-Based Diesel Fuels: Part 2. The Effect of Oxygenate Blending Compounds on Exhaust Emissions", SAE Trans. 101 (2001). SAE-2001-01-3632.

5. Musculus, M.P., Dec, J.E., and Tree, D.R., "Effects of Fuel Parameters and Diffusion Flame Lift-Off on Soot Formation in a Heavy-Duty Diesel Engine", Society of Automotive Engineers paper SAE-2002-01-0889 (2002).

6. Choi, C.Y., and Reitz, R.D., Fuel 78 , 1303-1317 (1999).

7. Mueller, C.J., and Martin, G.C., "Effects of Oxygenated Compounds on Combustion and Soot Evolution in a DI Diesel Engine: Broadband Natural Luminosity Imaging", Society of Automotive Engineers paper SAE-2002-011631 (2002). 
8. Stoner, M., and Litzinger, T.A., "Effects of Structure and Boiling Point of Oxygenated Blending Compounds in Reducing Diesel Emissions", Society of Automotive Engineers paper SAE-1999-01-1475 (1999).

9. Mueller, C.J., Pitz, W.J., Pickett, L.M., Martin, G.C., Siebers, D.L., and Westbrook, C.K.,"Effects of Oxygenates on Soot Processes in DI Diesel Engines: Experiments and Numerical Simulations", Society of Automotive Engineers SAE 2003-01-1791 (2003).

10. Buchholz, B.A., Mueller, C.J., Upatnieks, A., Martin, G.C., Pitz, W.J., and Westbrook, C.K., “Using Carbon-14 Isotope Tracing to Investigate Molecular Structure Effects on the Oxygenate Dibutyl Maleate on Soot Emissions from a DI Diesel Enging", Society of Automotive Engineers paper SAE 2004-011849 (2004).

11. Kitamura, T., Ito, T., Kitamura, Y., Ueda, M., Senda, J., and Fujimoto, H., “Soot Kinetic Modeling and Empirical Validation on Smokeless Diesel Combustion with Oxygenated Fuels", Society of Automotive Engineers paper SAE 2003-01-1789 (2003).

12. McNesby, K.L., Miziolek, A.W., Nguyen, T., Delucia, F.C., Skaggs, R.R., and Litzinger, T.A., Combust. Flame 142, 413-427 (2005).

13. Wu, J., Song, K.H., Litzinger, T., Lee, S.-Y., Santoro, R., and Linevsky, M., Combust. Flame, in press (2005).

14. Song, K.H., Nag, P., Litzinger, T.A., and Haworth, D.C., Combust. Flame 135, 341-349 (2003).

15. Dec, J.E., "A Conceptual Model of DI Diesel Combustion Based on LaserSheet Imaging", Society of Automotive Engineers paper SAE 970873 (1997). 
16. Dec. J.E., and Espey, C., “Society of Automotive Engineers SAE 980147 (1998).

17. Dec, J.E., and Espey, C., "Ignition and Early Soot Formation in a DI Diesel Engine Using Multiple 2-D Imaging Diagnostics", SAE Trans. 104, Sec. 3, 853-875 (1995). SAE 950456.

18. Dec, J.E.., “Soot Distribution in a DI Diesel Engine Using 2-D Imaging of Laser-Induced Incandescence, Elastic Scattering, and Flame Luminosity", SAE Trans. 101, Sec. 4, 101-112, (1992). SAE-920115.

19. Dec. J.E., and Espey, C., “Soot and Fuel Distributions in a DI Diesel Engine Via 2-D Imaging", SAE Trans. 101, Sec. 4, 1642-1651 (1992). SAE-922307.

20. Espey, C., Dec, J.E., Litzinger, T.A., and Santavicca, D.A., “Quantitative 2-D Fuel Vapor Concentration Imaging in a Firing DI Diesel Engine Using Planar Laser-Induced Rayleigh Scattering", SAE Trans. 103, Sec. 3, 1145-1160 (1994). SAE 940682.

21. Flynn, P.F., Durrett, R.P., Hunter, G.L., zur Loye, A.O., Akinyemi, O.C., Dec, J.E., and Westbrook, C.K., “Diesel Combustion: An Integrated View Combining Laser Diagnostics, Chemical Kinetics, and Empirical Validation", SAE Trans. 108, Sec. 3, 587-600 (1999). SAE-1999-01-0509.

22. Frenklach, M., and Wang, H., Proc. Combust. Inst. 23 1559-1566 (1990).

23. Appel, J., Bockhorn, H., and Frenklach, M., Combust. Flame 121, 122-136 (2000).

24. Wagner, H.Gg., "Soot Formation - An Overview”, pp. 1-29, Particulate Carbon Formation During Combustion, D.C. Siegla and G.W. Smith, eds., Plenum Press, New York, 1981. 
25. Harris, S.J., Weiner, A.M., Blint, R.J., and Goldsmith, J.E.M., Proc. Combust. Inst. 21, 1033-1045 (1986).

26. Richter, H., and Howard, J.B., Prog. Energy Combust. Sci. 26, 565-608 (2000).

27. Bockhorn, H., Fetting, F., and Wenz, H.W., Ber. Bunsenges. Phys. Chem. $\underline{87}$ 1067-1073 (1983).

28. Homann, K.H., Combust. Flame 11, 265-287 (1967).

29. Haynes, B.S., and Wagner, H.Gg., Prog. Energy Combust. Sci. $\underline{7}, 229-273$ (1981).

30. Marinov, N. M., Pitz, W. J., Westbrook, C. K., Vincitore, A. M., Castaldi, M. J., Senkan, S. M., and Melius, C. F., Combust. Flame 114, 192-213 (1998).

31. Miller, J.A., Pilling, M.J., and Troe, J., Proc. Combust. Inst. $\underline{30}$, 43-88 (2005).

32. McEnally, C.S., Ciuparu, D.M., and Pfefferle, L.D., Combust. Flame 134, 339353 (2003).

33. Curran, H.J., Gaffuri, P., Pitz, W.J., and Westbrook, C.K., Combust. Flame 114, 149-177 (1998).

34. Yelvington, P.E., Rallo, M.B.I., Liput, S., Tester, J.W., Green, W.H., and Yang, J.L., Combust. Sci. Technol. 176, 1243-1282 (2004).

35. Hamosfakidis, V., and Reitz, R.D., Combust. Flame 132, 433-450 (2003).

36. Samec, N., Kegl, B., and Dibble, R.W., Fuel 81, 2035-2044 (2002).

37. Lee, K., Lee, C., Ryu, J., and Kim, H., Energy \& Fuels 19, 393-402 (2005).

38. Su, W.H., and Huang, H.Z., Fuel 84 1029-1040 (2005).

39. Naber, J.D., and Siebers, D.L., "Effects of Gas Density and Vaporization on Penetration and Dispersion of Diesel Sprays", Society of Automotive Engineers paper SAE 960034 (1996).

40. http://www-cms.llnl.gov/combustion/combustion2.html 
41. Westbrook, C. K., and Dryer, F. L., Combust. Sci. Tech. 20, 125-140 (1979).

42. Marinov, N.M., Int. J. Chem. Kinet. $\underline{31}$ 183-220 (1999).

43. Curran, H.J., Pitz, W.J., Westbrook, C.K., Dagaut, P., Boettner, J.C., and Cathonnet, M., Int. J. Chem. Kinet. 30, 229-241 (1998).

44. Fischer, S.L., Dryer, F.L., and Curran, H.J., Int. J. Chem. Kinet. 32, 713-740 (2000).

45. Curran, H.J., Fischer, S.L., and Dryer, F.L., Int. J. Chem. Kinet. 32, 741-759 (2000).

46. Zheng, X.L., Lu, T.F., Law, C.K., Westbrook, C.K., and Curran, H.J., Proc. Combust. Inst. 30 1101-1109 (2005).

47. Glaude, P.A., Pitz, W.J., and Thomson, M.J., Proc. Combust. Inst. 30, 11111118 (2005).

48. Fisher, E. M., Pitz, W. J., Curran, H. J., and Westbrook, C. K., Proc. Combust. Inst. 28, 1579-1586 (2000).

49. Benson, S.W., Thermochemical Kinetics, 2nd edition, John Wiley, New Yourk, 1976.

50. Ritter, E.R., and Bozzelli, J.W., Int. J. Chem. Kinet. 23, 767-778 (1991).

51. Lay, T., Bozzelli, J.W., Dean, A.M., and Ritter, E.R., J. Phys. Chem. 99, 1451414527 (1995).

52. Zhu, L., Chen, C.J., and Bozzelli, J.W., J. Phys. Chem. A 104, 9197-9206 (2000).

53. Siebers, D., and Higgins, B., "Flame Lift-Off on Direct-Ignition Diesel Sprays Under Quiescent Conditions", Society of Automotive Engineers paper 200101-0530 (2001).

54. Graboski, M.S., and McCormick, R.L., Prog. Energy Combust. Sci. 24, 125-164 (1998). 
55. McCunn, L.R., Lau, K.-C., Krisch, M.J., Butler, L.J., Tsung, J.-W., and Lin, J.J., J. Phys. Chem. A, in press (2005).

56. Good, D.A., and Francisco, J.S., J. Phys. Chem. A 104, 1171-1185 (2000).

57. Szybist, J.P., and Boehman, A.L., submitted for publication (2005).

58. Curran, H.J., Fisher, E.M., Glaude, P.-A., N.M. Marinov, W.J. Pitz, Westbrook, C.K., Layton, D.W., Flynn, P.F., Durrett, R.P., zur Loye, A.O., Akenyemi, O.C., and Dryer, F.L., “Detailed Chemical Kinetic Modeling of Diesel Combustion with Oxygenated Fuels", Society of Automotive Engineers paper SAE 2001-01-0097 (2001).

59. Zannis, T.C., Hountalas, D.T., and Kouremenos, D.A., “Experimental Investigation to Specify the Effect of Oxygenated Additive Content and Type on DI Diesel Engine Performance and Emissions", Society of Automotive Engineers paper SAE 2004-01-0097 (2004). 